\title{
ORIGINAL
}

\section{Effects of levosimendan on respiratory muscle function in patients weaning from mechanical ventilation}

\author{
Lisanne Roesthuis ${ }^{1}$, Hans van der Hoeven ${ }^{1}$, Christer Sinderby ${ }^{2,3,4}$, Tim Frenzel ${ }^{1}$, Coen Ottenheijm ${ }^{5,6}$,
} Laurent Brochard ${ }^{2,7}$, Jonne Doorduin ${ }^{8}$ and Leo Heunks ${ }^{* *}$

(c) 2019 The Author(s)

\begin{abstract}
Purpose: Respiratory muscle weakness frequently develops in critically ill patients and is associated with adverse outcome, including difficult weaning from mechanical ventilation. Today, no drug is approved to improve respiratory muscle function in these patients. Previously, we have shown that the calcium sensitizer levosimendan improves calcium sensitivity of human diaphragm muscle fibers in vitro and contractile efficiency of the diaphragm in healthy subjects. The main purpose of this study is to investigate the effects of levosimendan on diaphragm contractile efficiency in mechanically ventilated patients.
\end{abstract}

Methods: In a double-blind randomized placebo-controlled trial, mechanically ventilated patients performed two 30-min continuous positive airway pressure (CPAP) trials with 5-h interval. After the first CPAP trial, study medication (levosimendan $0.2 \mu \mathrm{g} / \mathrm{kg} / \mathrm{min}$ continuous infusion or placebo) was administered. During the CPAP trials, electrical activity of the diaphragm $\left(E_{\mathrm{di}}\right)$, transdiaphragmatic pressure $\left(P_{\mathrm{di}}\right)$, and flow were measured. Neuromechanical efficiency (primary outcome parameter) was calculated.

Results: Thirty-nine patients were included in the study. Neuromechanical efficiency was not different during the CPAP trial after levosimendan administration compared to the CPAP trial before study medication. Tidal volume and minute ventilation were higher after levosimendan administration (11 and 21\%, respectively), whereas EA $A_{\mathrm{di}}$ and $P_{\mathrm{di}}$ were higher in both groups in the CPAP trial after study medication compared to the CPAP trial before study medication.

Conclusions: Levosimendan does not improve diaphragm contractile efficiency.

Keywords: Diaphragm, Critical-illness-associated respiratory muscle weakness, Mechanical ventilation weaning, Calcium sensitization, Levosimendan

\footnotetext{
*Correspondence: I.heunks@amsterdamumc.nl

${ }^{9}$ Department of Intensive Care Medicine, Amsterdam UMC, location

VUmc, Postbox 7057, 1007 MB Amsterdam, The Netherlands

Full author information is available at the end of the article
}

\section{重




\section{Introduction}

Respiratory muscle weakness frequently develops in ventilated critically ill patients and is associated with adverse outcome, including difficult weaning from mechanical ventilation [1-10]. Therefore, strategies that aim to improve respiratory muscle function are much needed. Today, no drug is approved for the treatment of respiratory muscle weakness [11].

Muscle weakness may result from loss of contractile proteins (atrophy) or contractile protein dysfunction. Indeed, atrophy of the diaphragm has been demonstrated in critically ill ventilated patients using ultrasound [8] and muscle biopsies $[12,13]$. Recently, we found evidence for contractile protein dysfunction in diaphragm muscle fibers of ventilated intensive care unit (ICU) patients [12]. Diaphragmatic muscle fibers of these patients exhibit reduced calcium sensitivity of contraction [14], resulting in decreased force generation at submaximal intracellular calcium concentration [12]. Levosimendan, a cardiac inotrope that augments the calcium sensitivity of the troponin complex, has been shown to improve cardiac muscle contractility and is approved for clinical application worldwide for treatment of heart failure $[15,16]$.

In an experimental study, we demonstrated that levosimendan improves in vitro force generation of slow and fast twitch muscle fibers obtained from the diaphragm of patients with chronic obstructive pulmonary disease (COPD), but also from fibers obtained from elective surgery patients without comorbidities [17]. More recently, we demonstrated that levosimendan improves in vivo contractile efficiency of the diaphragm in healthy subjects [18]. Whether levosimendan improves in vivo contractile efficiency of the diaphragm in ICU patients has not been evaluated. Based on our previous studies in vitro [17] and in vivo [18], we hypothesized that levosimendan improves diaphragm contractile efficiency in patients weaning from mechanical ventilation. We conducted a double-blinded randomized placebo-controlled trial that aims to investigate the effects of levosimendan on respiratory muscle function, especially diaphragm contractile efficiency in ventilated ICU patients.

\section{Methods}

\section{Study design and population}

The study was a double-blind randomized placebocontrolled trial conducted in the ICU of the Radboud University Nijmegen Medical Center. Inclusion criteria were invasive mechanical ventilation for at least 3 days, inspiratory pressure support $(\mathrm{PS}) \leq 10 \mathrm{cmH}_{2} \mathrm{O}$, positive end-expiratory pressure (PEEP) $\leq 10 \mathrm{cmH}_{2} \mathrm{O}, \mathrm{P} / \mathrm{F}$ ratio $\geq 200 \mathrm{mmHg}$, hemodynamically stable (systolic blood pressure $\geq 110 \mathrm{mmHg}$ without or with low dose

\section{Take-home message}

The calcium sensitizer levosimendan is approved as a cardiac inotrope, but preliminary studies have shown that it may also improve respiratory muscle function. This randomized placebo controlled trial shows that levosimendan improves tidal volume, minute ventilation and lowers arterial $\mathrm{CO}_{2}$ in patients weaning from mechanical ventilation

vasopressors), and able to sustain a 30-min continuous positive airway pressure (CPAP) trial. Exclusion criteria were neuromuscular disorder before ICU admission, new onset cardiac arrhythmias, left ventricle ejection fraction $<35 \%$, severe kidney failure (serum creatinine $>150 \mu \mathrm{mol} / \mathrm{L}$ ), pregnancy or contra-indication for the placement of nasogastric tube (upper airway or esophageal pathology, recent nasal bleeding). The protocol was approved by the local ethical committee and registered at ClinicalTrials.gov (NCT01721434). Written informed consent was obtained from the legal representative before inclusion.

\section{Trial design}

Patients were ventilated with the Servo-i ventilator (Maquet, Sölna, Sweden). After enrollment, a multi-electrode nasogastric catheter with esophageal and gastric balloon (NeuroVent Research Inc, Toronto, Canada) was inserted through the nose. The catheter was positioned to obtain the best electrical activity of the diaphragm $\left(E A_{d i}\right)$ signal using software supplied with the ventilator [19]. $\mathrm{EA}_{\mathrm{di}}$ is a processed electromyographic (EMG) signal obtained from an esophageal multi-electrode recording of the diaphragm. The exact processing algorithm is proprietary, but roughly based on the processing algorithms of Sinderby and colleagues [20-22]. All patients were already equipped with an arterial catheter for blood pressure monitoring, a pulse oximeter, and ECG monitoring. Allocation to placebo or levosimendan occurred by block design (ratio of 1:1 to receive placebo or levosimendan). Placebo (riboflavin sodium phosphate $0.4 \mathrm{mg}$, dehydrated alcohol $100 \mathrm{mg}$ and water $1 \mathrm{~mL}$ ), and levosimendan were indistinguishable (both yellowish) to assure appropriate blinding. Each patient performed two 30-min CPAP trails with $5 \mathrm{~h}$ in between. During these two CPAP trials, inspiratory assist was reduced to zero, while PEEP level was maintained as determined by the treating physician. Thirty minutes after the first CPAP trial [i.e., at study time (hours:minutes) $T=1: 00]$, study medication [levosimendan $0.2 \mu \mathrm{g} / \mathrm{kg} / \mathrm{min}$ or placebo (equal volume)] was administered intravenously till $30 \mathrm{~min}$ after the second CPAP trial. Arterial blood was withdrawn before and after CPAP trials. After the second CPAP trial, the study ended and standard clinical treatment was continued. 


\section{Data acquisition}

Airway flow and processed EAdi were obtained (sampling rate $100 \mathrm{~Hz}$ ) by connecting a RS-232 cable via the serial port of the Servo-i to a personal computer and resampled to $2 \mathrm{kHz}$. Esophageal $\left(P_{\mathrm{es}}\right)$ and gastric pressures $\left(P_{\mathrm{ga}}\right)$ were obtained (sampling rate $2 \mathrm{kHz}$ ) from the two balloons mounted on the esophageal catheter and connected to two differential pressure transducers (range $\pm 50 \mathrm{kPa}$, Freescale, Tempe, AR) and A/D converter (DT3004; Data Translation, USA). All signals were acquired continuously and synchronously using dedicated software (NeuroVent Research Inc, Toronto, Canada). Signals were analyzed offline using Matlab R2014b (Mathworks, Natick, MA, USA).

\section{Data analysis}

Transdiaphragmatic pressure $\left(P_{\mathrm{di}}\right)$ was calculated as $P_{\mathrm{ga}}$ minus $P_{\mathrm{es}}$, from this, $\Delta P_{\mathrm{di}}$ was defined as the difference between the start of increase in $P_{\mathrm{di}}$ and the peak value of $P_{\mathrm{di}}$ during inspiration. Inspiratory flow was integrated for the calculation of tidal volume $(T V)$. Respiratory rate, minute ventilation, and inspiratory time $\left(T_{\mathrm{i}}\right)$ were determined from the flow signal. $\Delta \mathrm{EA}_{\mathrm{di}}$ was computed as the peak from the processed $\mathrm{EA}_{\mathrm{di}}$ signal obtained from the Servo-i during inspiration. Neuromechanical efficiency (NME) was calculated as $\Delta P_{\mathrm{di}} l$ $\triangle \mathrm{EA}_{\text {di }}$. Intrinsic PEEP (PEEPi) was computed as the difference in pressure between start of increase in $P_{\mathrm{di}}$ and start of inspiratory flow [23]. $P_{0.1}$, a measure of respiratory drive, was calculated as the decrease in $P_{\text {es }}$ during the first $100 \mathrm{~ms}$ of inspiration [24]. Dynamic lung compliance $\left(C_{\mathrm{dyn}}\right)$ was computed as $\mathrm{TV} / \Delta P_{\mathrm{es}}$.

Data were analyzed on a breath-by-breath basis and averaged over a 2-min period free of artifacts or esophageal or gastric contractions. For each CPAP trial, four points in time were analyzed: study time (hours:minutes) $T=0: 01,0: 05,0: 15$, and 0:30 for CPAP 1 and $T=5: 31,5: 35,5: 45$, and 6:00 for CPAP 2 .

\section{Sample size calculation and statistical analysis}

The primary outcome parameter is the difference in diaphragm NME response between placebo and levosimendan. NME was calculated at the end of both 30-min CPAP trials before and after study medication. Previously, we found a mean NME of $1.3 \mathrm{cmH}_{2} \mathrm{O} / \mu \mathrm{V}$ with a standard deviation of $0.5 \mathrm{~cm} \mathrm{H}_{2} \mathrm{O} / \mu \mathrm{V}$, in response to administration of levosimendan neuromechanical efficiency increased by $21 \%$ [18]. Therefore, if we expect in the current study an increase in neuromechanical efficiency of $25 \%$, this would mean a minimal detected difference of $0.33 \mathrm{cmH}_{2} \mathrm{O} / \mu \mathrm{V}$. When we assume a type I error of 0.05 (two sided) and type II error of 0.80 , the calculated sample size is 19 patients per study arm.

Statistical analysis was performed using IBM SPSS Statistics version 22 (IBM Corp, Armonk, New York, USA). Continuous variables were compared using a Student's $t$ test in case data had a normal distribution and MannWhitney $U$ test in case of a non-normal distribution. A Chi-square test with either normal approximation or Fisher's exact test was used to compare nominal categorical variables. To assess the effect of levosimendan on respiratory and hemodynamic parameters, a two-way repeated measures ANOVA was used, with time (for respiratory parameters study time (hours:minutes) $T=0: 30$ and 6:00; in addition, for hemodynamic parameters also at $T=0: 01,1: 00$ and 5:31) as the within-subject factor and group (study medication) as the between-subject factor. In case data were non-normally distributed, first, a $\log$ transformation was performed to obtain a normal distribution. Data are presented as mean \pm SEM in case of a normal distribution and median (IQR) as stated otherwise. A two-tailed $P<0.05$ was considered statistically significant.

\section{Results}

\section{Patient characteristics}

Thirty-nine subjects received study medication and completed the entire study protocol. Baseline characteristics for both groups are shown in Table 1. Two subjects were excluded from analysis of the primary endpoint (one from the placebo and one from the levosimendan group), one due to technical issues related to the nasogastric catheter, and another due to low $\mathrm{EA}_{\mathrm{di}}$ precluding analysis of the primary endpoint. From the remaining subjects, 18 received placebo and 19 received levosimendan.

\section{Effects of levosimendan on respiratory variables}

Table 2 shows the absolute $\operatorname{NME}\left(\Delta P_{\mathrm{di}} / \Delta \mathrm{EA}_{\mathrm{di}}\right)$ and Fig. 1a shows the normalized NME (NME normalized with respect to start of the CPAP trial without study medication [i.e. $T=0: 01$ ] over the course of the study. As expected, NME before study medication was not different between groups at start of the first CPAP trial and remained stable during the first CPAP trial in both groups. Levosimendan did not significantly affect diaphragm NME $(P=0.407) \quad$ (from $1.2 \pm 0.2$ to $1.1 \pm 0.2 \mathrm{cmH}_{2} \mathrm{O} / \mu \mathrm{V}$ ) compared to placebo (from $1.7 \pm 0.5$ to $2.1 \pm 0.8 \mathrm{cmH}_{2} \mathrm{O} / \mu \mathrm{V}$ ) assessed after $30 \mathrm{~min}$ of CPAP.

$\Delta P_{\mathrm{di}}$ and $\Delta \mathrm{EA}_{\mathrm{di}}$ were higher in both the levosimendan and placebo groups in the CPAP trial after study medication as compared to before study medication (Fig. $1 \mathrm{~b}$ and Table 2). 
Table 1 Patient characteristics

\begin{tabular}{|c|c|c|c|}
\hline & Placebo $(n=19)$ & Levosimendan $(n=20)$ & $P$ value \\
\hline Age (yr) & $63(51-71)$ & $67(56-69)$ & 0.53 \\
\hline BMI $\left(\mathrm{kg} / \mathrm{m}^{2}\right)$ & $26.0(23.6-28.9)$ & $24.6(23.3-27.3)$ & 0.69 \\
\hline Gender (M/F) & $13 / 6$ & $10 / 10$ & 0.24 \\
\hline \multicolumn{4}{|l|}{ Reason ICU admittance, no. (\%) } \\
\hline Neurological & $3(16)$ & $0(0)$ & 0.11 \\
\hline Pneumonia & $1(5)$ & $4(20)$ & 0.34 \\
\hline Sepsis non-respiratory focus & $3(16)$ & $3(15)$ & $>0.99$ \\
\hline Post-surgery & $4(21)$ & $6(30)$ & 0.52 \\
\hline Exacerbation COPD & $2(11)$ & $0(0)$ & 0.23 \\
\hline Trauma & $4(21)$ & $4(20)$ & $>0.99$ \\
\hline Other & $2(11)$ & $3(15)$ & $>0.99$ \\
\hline Days of MV on study day & $11(7-23)$ & $12(5-18)$ & 0.61 \\
\hline PS level $\left(\mathrm{cmH}_{2} \mathrm{O}\right)$ & $6(6-10)$ & $8(6-9.5)$ & 0.75 \\
\hline PEEP level $\left(\mathrm{cmH}_{2} \mathrm{O}\right)$ & $6(5-10)$ & $7(5-8)$ & 0.55 \\
\hline $\mathrm{PaO}_{2} / \mathrm{FiO}_{2}$ ratio $(\mathrm{mmHg})$ & $268(233-306)$ & $319(256-377)$ & 0.08 \\
\hline \multicolumn{4}{|l|}{ Comorbidities, no. (\%) } \\
\hline COPD & $8(42)$ & $4(20)$ & 0.14 \\
\hline Diabetes mellitus & $4(21)$ & $4(20)$ & $>0.99$ \\
\hline Cancer & $1(5)$ & $2(11)$ & $>0.99$ \\
\hline \multicolumn{4}{|l|}{ Relevant treatment at time of study, no. (\%) } \\
\hline Norepinephrine & $2(11)$ & $6(30)$ & 0.24 \\
\hline Steroids & $6(32)$ & $3(15)$ & 0.27 \\
\hline Dobutamine & $0(0)$ & $0(0)$ & $>0.99$ \\
\hline Milrinon & $0(0)$ & $0(0)$ & $>0.99$ \\
\hline RASS CPAP trial before study medication & $0(-1$ to 0$)$ & -1 ( -3 to 0$)$ & 0.04 \\
\hline RASS CPAP trial after study medication & $0(-1$ to 0$)$ & $-1(-3$ to 0$)$ & 0.09 \\
\hline Delirious, no. (\%) & $1(5)$ & $5(25)$ & 0.18 \\
\hline
\end{tabular}

Data are presented as median (IQR)

$B M I$ body mass index, $M V$ mechanical ventilation, $P S$ pressure support, $P E E P$ positive end-expiratory pressure, COPD chronic obstructive pulmonary disease, RASS Richmond Agitation Sedation scale

Before study medication, tidal volume was equal between groups during the CPAP trial, but after study medication, there was a larger increase $(P=0.017)$ in tidal volume during CPAP in the levosimendan group (from $392 \pm 22$ to $437 \pm 23 \mathrm{~mL}$ ) compared to the placebo group (from $404 \pm 32$ to $418 \pm 33 \mathrm{~mL}$ ) (Fig. 1c). In addition, minute ventilation increased significantly more after levosimendan administration $(P=0.021)$ (Fig. 1d). Increased minute ventilation resulted in decreased $\mathrm{PaCO}_{2}$ and increased $\mathrm{pH}$ in patients treated with levosimendan (Table 2).

Table 2 also shows the absolute NME, $\Delta \mathrm{EA}_{\mathrm{di}}, P_{0.1}, C_{\mathrm{dyn}}$, $\mathrm{PEEPi}$, respiratory rate, and inspiratory time over the course of the study.

\section{Effects of levosimendan on hemodynamics}

Levosimendan decreased mean arterial blood pressure (MAP) by $10 \%$ between the end of the CPAP trial before study medication ( $T=0: 30)$ and start of the CPAP trial after study medication ( $T=5: 31)$ (Fig. 2a, $P<0.001$ ). Compared to the placebo group, MAP in the levosimendan group was lower at the start of the CPAP trial after study medication ( $T=5: 31$ ) (MAP levosimendan $77 \pm 3$ and placebo $89 \pm 4 \mathrm{mmHg} ; P=0.031)$.

In the levosimendan group, heart rate increased between start of administration of study medication $(T=1: 00)$ and start of the CPAP trial after study medication $(T=5: 31)$ (Fig. 2b, $P=0.046)$.

\section{Adverse events}

No serious adverse events occurred between start of study protocol and $24 \mathrm{~h}$ after the end of the CPAP trial after study medication. Ten of 19 patients in the levosimendan group (one missing value due to technical reasons) developed hypotension (defined as systolic blood pressure $<100 \mathrm{mmHg}$ or a decrease $\geq 20 \%$ ) compared to 6 patients in the placebo group $(P=0.19)$. Five patients 


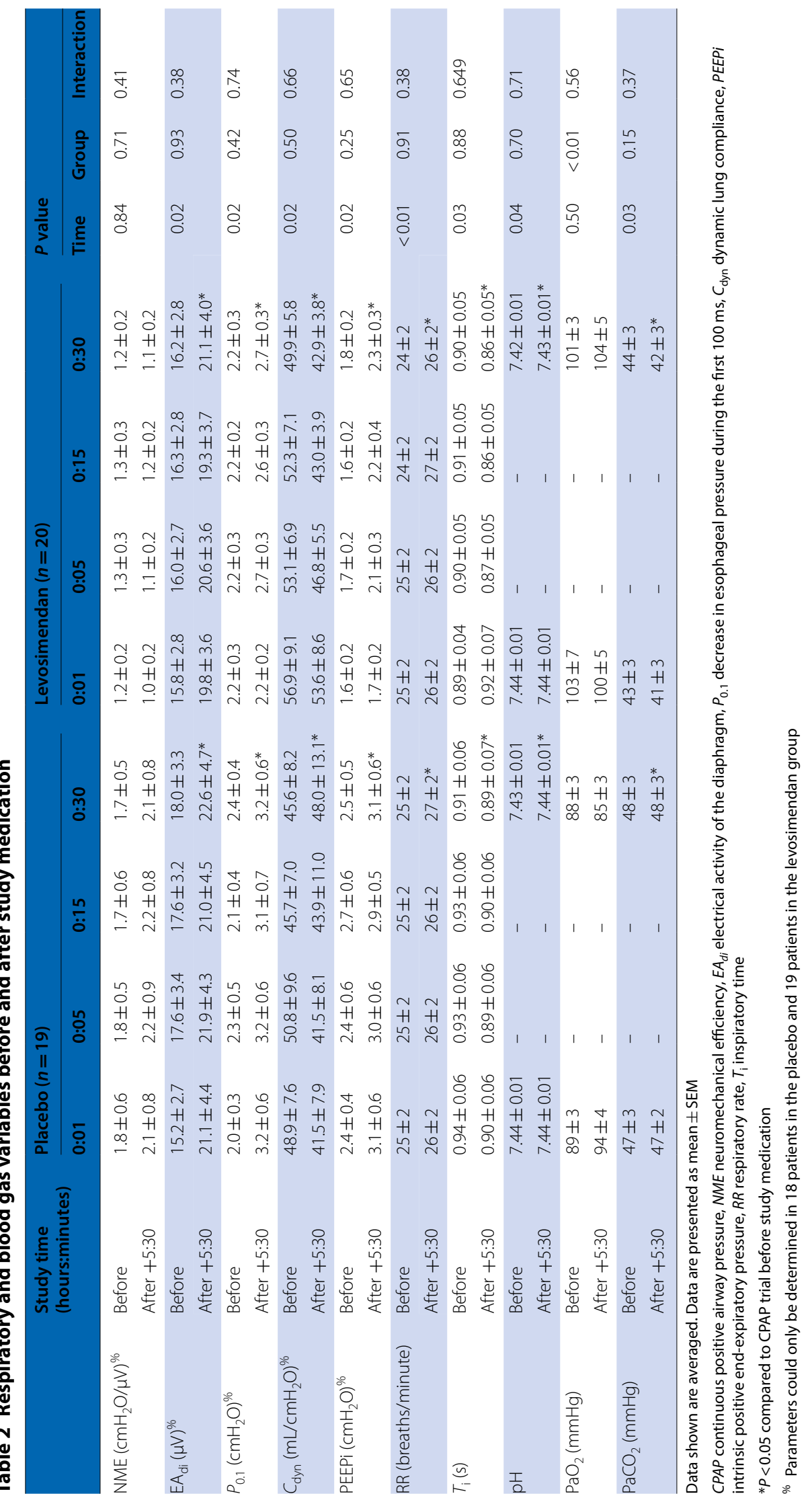



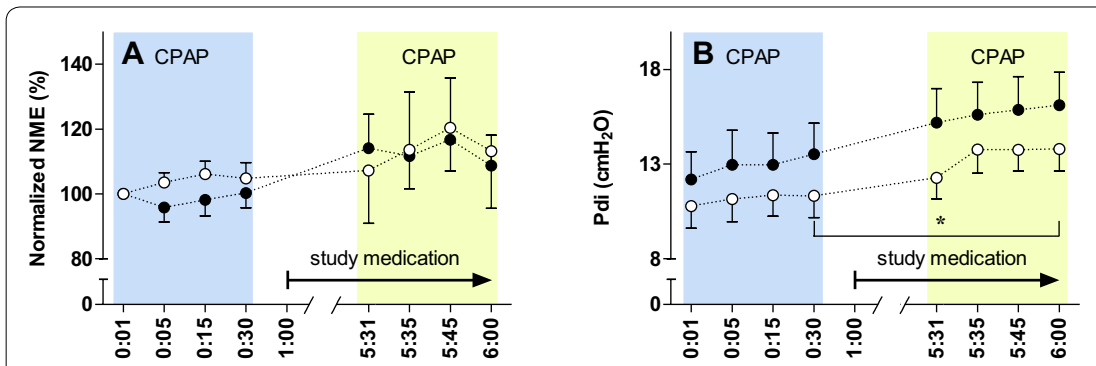

-.. placebo

o.. levosimendan
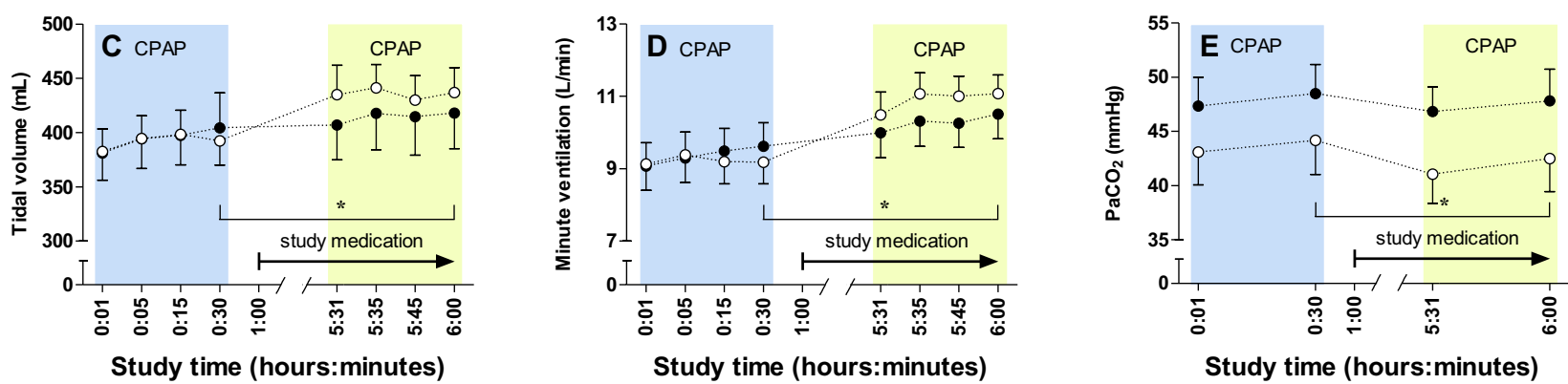

Fig. 1 Respiratory parameters over the course of the study day during the continuous positive airway pressure (CPAP) trial before (blue) and after (yellow) study medication for the placebo (closed circles) and levosimendan (open circles) groups. a Neuromechanical efficiency (NME) was normalized to the start point of the first CPAP trial [study time (hours:minutes) $T=0: 01$ ]. NME was not different between the placebo and levosimendan groups and did not increase in the continuous positive airway pressure (CPAP) trial after administration of levosimendan (primary outcome; $P=0.407)$. b Transdiaphragmatic pressure $\left(\triangle P_{\text {di }}\right)$ increased during the study day and was higher in the placebo and levosimendan groups in the CPAP trial after study medication as compared to the CPAP trial before study medication $(P<0.001)$. c Tidal volume increased during the study day in both groups, but increased significantly more after levosimendan administration as compared to the placebo group and as compared to the CPAP trial before study medication $(P=0.017)$. The same was true for minute ventilation $(\mathbf{d})$, which also increased in both groups during the study day, but significantly more after levosimendan administration $(P=0.021)$. e $\mathrm{PaCO}_{2}$ was higher in both groups in the CPAP trial after study medication as compared to the CPAP trial before study medication ( $P=0.032$ ). Tidal volume and minute ventilation could be determined in all patients $(n=39)$. The other parameters could be determined in 36 patients on time points, minute 1 and 5 during the CPAP trial before study medication ( $T=0: 01$ and $T=0: 05)$ and in 37 patients on the remaining time points. Data are presented as mean \pm SEM. ${ }^{*}$ Significantly different between CPAP trials

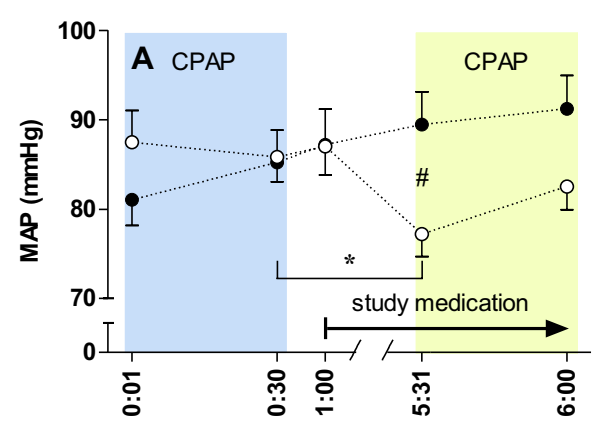

Study time (hours:minutes)

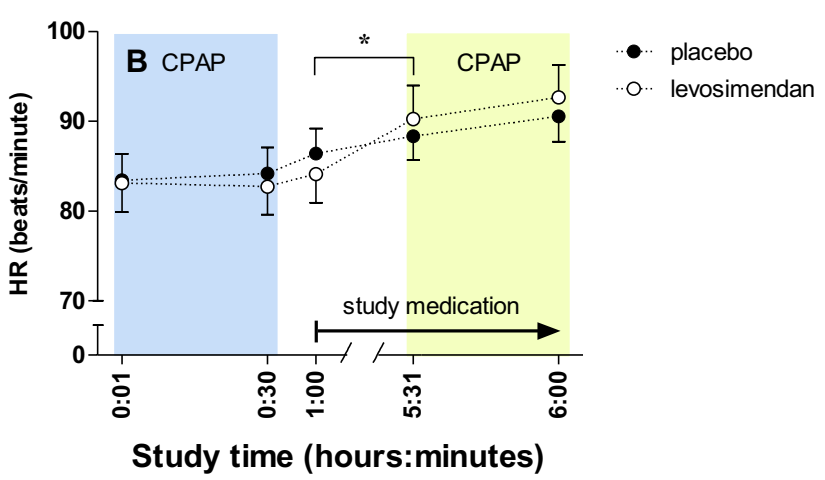

Study time (hours:minutes)

Fig. 2 Hemodynamic parameters during the study in the placebo (closed circles) and levosimendan groups (open circles). a Mean arterial blood pressure (MAP) was reduced at the start of the continuous positive airway pressure (CPAP) trial after study medication [study time (hours:minutes) $T=5: 31]$ compared to the end of the CPAP trial before study mediation ( $T=0: 30)$ only in the levosimendan group $(P<0.001)$, in addition, MAP at the start of the CPAP trial after study medication $(T=5: 31)$ was lower in the levosimendan group compared to the placebo group $(P=0.031)$. $\mathbf{b} \mathrm{In}$ both groups, heart rate increased during the study day $(P<0.001)$. Only in the levosimendan group, heart rate was higher at the start of the CPAP trial after study medication ( $T=5: 31)$ compared to the start of study medication $(T=1: 00)(P=0.046)$. Data are presented as mean $\pm S E M$ (placebo $n=19$, levosimendan $n=20$ ). "Significantly different between time points in levosimendan group, "\#ignificantly different between levosimendan and placebo group 
required volume therapy after levosimendan administration compared to one patient in the placebo group $(P=0.18)$.

\section{Discussion}

This is the first study to investigate the effects of levosimendan on diaphragm function in mechanically ventilated ICU patients. The main findings of this physiological double-blind randomized placebo-controlled trial can be summarized as follows: first, we found no effect of levosimendan on diaphragm contractile efficiency. These findings are partly unexpected, given our previous studies that demonstrated that levosimendan improves in vitro contractile efficiency of the diaphragm in elective surgery patients and patients with COPD [17], and also in vivo function of the diaphragm in healthy subjects [18]. Second, administration of levosimendan increased tidal volume, increased minute ventilation, and decreased $\mathrm{PaCO}_{2}$. Third, no severe adverse events were reported after the administration of levosimendan.

\section{Effects of levosimendan on diaphragm function}

Critical-illness-associated respiratory muscle weakness may result from loss of contractile proteins (atrophy) or contractile protein dysfunction [5]. Indeed, only a few hours of controlled mechanical ventilation are associated with diaphragm atrophy in brain-dead patients $[9,13]$ and in patients after elective surgery [9]. More recently, we reported the development of atrophy in diaphragm muscle fibers of critically ill ventilated patients [12]. Using ultrasound, Goligher et al. [8] demonstrated progressive loss of diaphragm muscle thickness in ventilated ICU patients with high inspiratory ventilator assist. Besides atrophy, diaphragm weakness in critically ill patients results from dysfunction of the remaining contractile proteins, especially reduced calcium sensitivity of force generation [12, 14]. Reduced calcium sensitivity implies that more calcium and thus neural input is required to generate force, which increases energy expenditure of muscle contraction.

Levosimendan is known as a cardiac inotrope, with vasodilating properties. On one hand, it acts by increasing the sensitivity of troponin $\mathrm{C}$ to calcium in myocardial fibers, hence leading to inotropy. In addition, levosimendan increases open probability of the mitochondrial adenosine triphosphate (ATP)-sensitive potassium channels in smooth muscle cells, thus resulting in vasodilation (for review, see [25]). Levosimendan is currently approved as an inotrope for acutely decompensated heart failure $[15,16,25]$. In recent years, we have provided convincing evidence that levosimendan improves contractility of the diaphragm [17, 18, 26]. For instance, in human diaphragm muscle fibers, levosimendan increases calcium sensitivity of contraction by $20-30 \%$ [17], which is expected to improve contractile efficiency. We have also demonstrated that the effects of levosimendan are more pronounced in slowtype fibers compared to fast-type fibers [17]. It should be noted that levosimendan does not increase maximum force-generating capacity of the muscle fibers, as maximum force is independent from calcium sensitivity at saturating calcium concentration. In vivo, levosimendan improved neuromechanical efficiency of the diaphragm by $\sim 21 \%$ during both unloaded and loaded breathing [18]. Moreover, levosimendan reversed the development of diaphragm fatigue after strenuous loaded breathing. Based on these encouraging results in vitro (increased calcium sensitivity of contraction) and in vivo (improved neuromechanical efficiency of the diaphragm), we designed the current study. In the current study, measurements were performed during a CPAP trial, because at the time the study was designed, a CPAP trial was a common type of weaning trial. We found that levosimendan did not improve contractile efficiency of the diaphragm in ventilated critically ill patients compared to placebo. However, we did observe a significant increase in tidal volume and minute ventilation in the levosimendan group compared to placebo, resulting in a decrease in $\mathrm{PaCO}_{2}$. Despite not being the primary endpoint, this outcome is clinically relevant as minute ventilation is the final common pathway of the respiratory system and sufficient minute ventilation is the key to successful weaning. The physiological mechanism for the increased minute ventilation remains speculative. First, these findings may be explained by an increase in central respiratory drive. As respiratory drive of the diaphragm (assessed by $\mathrm{EA}_{\mathrm{di}}$ ) was not different after levosimendan, it can only be explained by altered drive to other muscles of the respiratory muscle pump, such as accessory inspiratory muscles or expiratory muscles [27]. Second, improved cardiac function may decrease pulmonary congestion and thus improve respiratory mechanics. However, dynamic lung compliance was not affected by levosimendan, making this explanation less likely.

Interestingly, both in placebo and levosimendan groups, the $\mathrm{EA}_{\mathrm{di}}$ and $P_{\mathrm{di}}$ increased in the second CPAP trial. Most likely, this reflects "normal" changes in respiratory drive during the day in ICU patients. As the first CPAP trial was performed early in the morning and the second in the afternoon, patients may have had some residual effects of sleep medication during the initial trial.

It should be noted that we expected that respiratory muscle function would improve in response to levosimendan regardless whether low levels of pressure support, CPAP or T piece with oxygen supply were used, 
because in healthy subjects, we found improved respiratory muscle function in response to levosimendan during both unloaded and loaded breathing [18].

\section{Explanations for unexpected findings}

There are a number of possible explanations why levosimendan did not improve efficiency of the diaphragm in the current study. First, a too low dose of the study drug. In contrast to our previous study [18], we did not administer a loading dose before continuous infusion of levosimendan. This was chosen to decrease the risk of severe hypotension, especially because weaning patients are often treated with diuretics. Nevertheless, the total dose administered before measurements was higher in the current study compared to our study in healthy subjects [18] (3.8 mg compared to $3.0 \mathrm{mg}$, respectively). Indeed, levosimendan resulted in a decrease in blood pressure (Fig. 2a), consistent with its vasodilatory effects $[15,25]$. In addition, the administered continuous dose was also based on previous sepsis trials in which equal dosages were administered [28]. Whether higher doses of levosimendan are effective to improve diaphragm function in ventilated ICU patients remains to be investigated. In the current study, half of the patients treated with levosimendan developed hypotension, half of them received fluid therapy. It is, therefore, expected, using higher doses of levosimendan, this will result in more pronounced hypotension in more patients.

Second, neuromechanical efficiency the diaphragm (NME; $\Delta P_{\mathrm{di}} / \Delta \mathrm{EA}_{\mathrm{di}}$ ) was chosen as the primary endpoint to evaluate diaphragm function. NME reflects the pressure the respiratory muscles can generate for each microvolt of electrical activity. Previously, we demonstrated in healthy subjects that levosimendan improves NME of the diaphragm [18]. The validity of NME as outcome parameter depends on the quality of the $P_{\mathrm{di}}$ and EA $\mathrm{Ad}_{\mathrm{di}}$ signals. In the current study, mean NME values appear to be higher in the placebo group, this is, however, due to low $\mathrm{EA}_{\mathrm{di}}$ in one patient, resulting in a high NME. A log transformation was applied prior to the two-way repeated measures ANOVA to obtain a normal distribution of the data. Recently, we reported that the $\mathrm{EA}_{\mathrm{di}}$ processing algorithm of the ventilator software may limit the clinical applicability of NME [29, 30]. 'Non-physiological' EA $\mathrm{di}_{\mathrm{i}}$ curves may occur as a result of flaws in the processing algorithm (e.g., removal of ECG) (Fig. E1 in Online Supplement), which affect the NME as well. In contrast to the current study, we used raw diaphragm EMG in our in vivo study in healthy subjects [18]. Another notable difference between the current study and our study in healthy subjects is that the healthy subjects had to perform inspiratory maneuvers of $10 \mathrm{~s}$ against a closed valve, resulting in a stable diaphragm EMG signal and, therefore, less vulnerable to artifacts as compared to the $\mathrm{EA}_{\mathrm{di}}$ signal obtained during a single inspiration in the current study. Besides technical issues regarding the primary endpoint, levosimendan has effects beyond calcium sensitization, including modulation of mitochondrial function and vasodilation [25]. This could have affected respiratory muscle function, independent from effects on NME. In a recent randomized controlled trial in patients with sepsis [31], levosimendan did not affect organ dysfunction (SOFA score) or mortality, but increased time to successful weaning. It should be noted that levosimendan in that study was administered very early after ICU admission and not in the weaning phase. Therefore, that study does not preclude a beneficial effect of levosimendan on patients weaning from mechanical ventilation.

Third, future studies should also consider the use of other calcium sensitizers, despite our earlier encouraging findings with levosimendan $[17,18,26]$. Alternatively, fast skeletal troponin activation might improve respiratory muscle function. Tirasemtiv amplifies the force response of the sarcomeres to calcium by slowing its dissociation rate from the troponin complex in fast-twitch muscle fibers [32]. Hooijman et al. [14] demonstrated that CK-2066260, an analog of tirasemtiv, increases the calcium sensitivity and restored contractile force of fast diaphragmatic muscle fibers of critically ill patients. The effects of CK-2066260 on diaphragm contractility in vivo have not been evaluated. Recently, however, tirasemtiv failed in a Phase 3 clinical trial in patients with amyotrophic lateral sclerosis due to its crossing the bloodbrain barrier [33].

\section{Strengths and limitations}

Previous studies demonstrating that levosimendan improves the calcium sensitivity of human diaphragm fibers in vitro $[17,26]$ and the contractile efficiency of the diaphragm in healthy subjects in vivo [18] provided a strong physiological rationale to perform the current study. In depth, physiological analysis of the diaphragm function was performed before and after study medication under controlled conditions (CPAP).

This study has some limitations. First, the endpoint, NME, has limited clinical relevance and the final effects of levosimendan on weaning success remain to be investigated. As the study protocol did not specifically describe criteria for extubation, reintubation, management for extubation failure, and so on, we did not report data on clinical outcome after the second CPAP trial. Second, we did not assess the effects of levosimendan on cardiac function, for instance, using cardiac ultrasound. We specifically excluded patients with past medical history of heart failure or current use of inotropes. Therefore, it was reasoned that changes in hemodynamic 
condition due to levosimendan were unlikely to affect the primary endpoint. Third, we did not measure $P_{\text {di-twitch, }}$, which is the gold standard to evaluate respiratory muscle function and can be measured upon magnetic or electrical stimulation of the phrenic nerves. We did not use this technique in the current study, because it can be technically challenging to perform, has limitations in tolerance, and cannot be applied in every patient [34]. Fourth, the calculated sample size was 38 patients. After finishing the study, it appeared that for only 37 patients the primary endpoint could be evaluated (one patient in each group was excluded). However, it seems unlikely that this would affect the primary outcome of the study.

In conclusion, this double-blind randomized placebocontrolled trial demonstrates that in patients weaning from mechanical ventilation, levosimendan failed to demonstrate a direct effect on diaphragm function, but does increase minute ventilation. The effects of levosimendan on weaning outcome remain to be studied.

\section{Electronic supplementary material}

The online version of this article (https://doi.org/10.1007/s00134-019-05767-y) contains supplementary material, which is available to authorized users.
(NVR). NVR is a research and development company that builds the equipment and catheters for research studies. Tim Frenzel: Declares no conflict of interest. Coen Ottenheijm: Declares no conflict of interest. Laurent Brochard: Laurent Brochard's laboratory has received grants and/or equipment for research projects from Medtronic Covidien, Philips, Sentec, Air Liquide, Fisher Paykel. Jonne Doorduin: Declares no conflict of interest. Leo Heunks: Has received speakers fee from Maquet Critical Care (Sweden) and Orion Pharma (Finland). His laboratory has received research grants a/o equipment from Liberate Medical (USA) and Maquet (Sweden).

\section{Ethical approval}

All procedures performed were in accordance with the ethical standards of the institutional and/or national research committee (CMO Regio ArnhemNijmegen NL-number 40137.091.12) and with the 1964 Helsinki Declaration and its later amendments or comparable ethical standards.

\section{Open Access}

This article is distributed under the terms of the Creative Commons Attribution-NonCommercial 4.0 International License (http://creativecommons.org/ licenses/by-nc/4.0/), which permits any noncommercial use, distribution, and reproduction in any medium, provided you give appropriate credit to the original author(s) and the source, provide a link to the Creative Commons license, and indicate if changes were made.

\section{Publisher's Note}

Springer Nature remains neutral with regard to jurisdictional claims in published maps and institutional affiliations.

Received: 8 July 2019 Accepted: 23 August 2019

Published online: 1 October 2019

\section{References}

1. Adler D, Dupuis-Lozeron E, Richard JC, Janssens JP, Brochard L (2014) Does inspiratory muscle dysfunction predict readmission after intensive care unit discharge? Am J Respir Crit Care Med 190(3):347-350. https:// doi.org/10.1164/rccm.201404-0655LE

2. Boles JM, Bion J, Connors A, Herridge M, Marsh B, Melot C, Pearl R, Silverman H, Stanchina M, Vieillard-Baron A, Welte T (2007) Weaning from mechanical ventilation. Eur Respir J 29(5):1033-1056. https://doi. org/10.1183/09031936.00010206

3. De Jonghe B, Bastuji-Garin S, Durand MC, Malissin I, Rodrigues P, Cerf C, Outin H, Sharshar T, Groupe de Reflexion et d'Etude des Neuromyopathies en R (2007) Respiratory weakness is associated with limb weakness and delayed weaning in critical illness. Crit Care Med 35(9):2007-2015

4. Demoule A, Molinari N, Jung B, Prodanovic H, Chanques G, Matecki S, Mayaux J, Similowski T, Jaber S (2016) Patterns of diaphragm function in critically ill patients receiving prolonged mechanical ventilation: a prospective longitudinal study. Ann Intensive Care 6(1):75. https://doi. org/10.1186/s13613-016-0179-8

5. Dres M, Goligher EC, Heunks LMA, Brochard LJ (2017) Critical illnessassociated diaphragm weakness. Intensive Care Med 43(10):1441-1452. https://doi.org/10.1007/s00134-017-4928-4

6. Funk GC, Anders S, Breyer MK, Burghuber OC, Edelmann G, HeindI W, Hinterholzer G, Kohansal R, Schuster R, Schwarzmaier-D'Assie A, Valentin A, Hartl S (2010) Incidence and outcome of weaning from mechanical ventilation according to new categories. Eur Respir J 35(1):88-94. https:// doi.org/10.1183/09031936.00056909

7. Goligher EC, Dres M, Fan E, Rubenfeld GD, Scales DC, Herridge MS, Vorona S, Sklar MC, Rittayamai N, Lanys A, Murray A, Brace D, Urrea C, Reid WD, Tomlinson G, Slutsky AS, Kavanagh BP, Brochard LJ, Ferguson ND (2018) Mechanical ventilation-induced diaphragm atrophy strongly impacts clinical outcomes. Am J Respir Crit Care Med 197(2):204-213. https://doi. org/10.1164/rccm.201703-05360C

8. Goligher EC, Fan E, Herridge MS, Murray A, Vorona S, Brace D, Rittayamai N, Lanys A, Tomlinson G, Singh JM, Bolz SS, Rubenfeld GD, Kavanagh BP, Brochard LJ, Ferguson ND (2015) Evolution of diaphragm thickness during mechanical ventilation. Impact of inspiratory effort. Am J Respir Crit 
Care Med 192(9):1080-1088. https://doi.org/10.1164/rccm.201503-0620o c

9. Jaber $S$, Petrof BJ, Jung B, Chanques G, Berthet JP, Rabuel C, Bouyabrine H, Courouble P, Koechlin-Ramonatxo C, Sebbane M, Similowski T, Scheuermann V, Mebazaa A, Capdevila X, Mornet D, Mercier J, Lacampagne A, Philips A, Matecki S (2011) Rapidly progressive diaphragmatic weakness and injury during mechanical ventilation in humans. Am J Respir Crit Care Med 183(3):364-371. https://doi.org/10.1164/rccm.201004-06700C

10. Penuelas O, Frutos-Vivar F, Fernandez C, Anzueto A, Epstein SK, Apezteguia C, Gonzalez M, Nin N, Raymondos K, Tomicic V, Desmery P, Arabi Y, Pelosi P, Kuiper M, Jibaja M, Matamis D, Ferguson ND, Esteban A, Ventila G (2011) Characteristics and outcomes of ventilated patients according to time to liberation from mechanical ventilation. Am J Respir Crit Care Med 184(4):430-437. https://doi.org/10.1164/rccm.201011-18870C

11. Schellekens WJ, van Hees HW, Doorduin J, Roesthuis LH, Scheffer GJ, van der Hoeven JG, Heunks LM (2016) Strategies to optimize respiratory muscle function in ICU patients. Crit Care 20(1):103. https://doi.org/10.1186/ s13054-016-1280-y

12. Hooijman PE, Beishuizen A, Witt CC, de Waard MC, Girbes AR, Spoelstrade Man AM, Niessen HW, Manders E, van Hees HW, van den Brom CE, Silderhuis V, Lawlor MW, Labeit S, Stienen GJ, Hartemink KJ, Paul MA, Heunks LM, Ottenheijm CA (2015) Diaphragm muscle fiber weakness and ubiquitin-proteasome activation in critically ill patients. Am J Respir Crit Care Med 191(10):1126-1138. https://doi.org/10.1164/rccm.20141 $2-22140 C$

13. Levine S, Nguyen T, Taylor N, Friscia ME, Budak MT, Rothenberg P, Zhu J, Sachdeva R, Sonnad S, Kaiser LR, Rubinstein NA, Powers SK, Shrager JB (2008) Rapid disuse atrophy of diaphragm fibers in mechanically ventilated humans. N Engl J Med 358(13):1327-1335. https://doi.org/10.1056/ NEJMoa070447

14. Hooijman PE, Beishuizen A, de Waard MC, de Man FS, Vermeijden JW, Steenvoorde P, Bouwman RA, Lommen W, van Hees HW, Heunks LM, Dickhoff C, van der Peet DL, Girbes AR, Jasper JR, Malik FI, Stienen GJ, Hartemink KJ, Paul MA, Ottenheijm CA (2014) Diaphragm fiber strength is reduced in critically ill patients and restored by a troponin activator. Am J Respir Crit Care Med 189(7):863-865. https://doi.org/10.1164/rccm.20131 2-2260LE

15. Papp Z, Edes I, Fruhwald S, De Hert SG, Salmenpera M, Leppikangas H, Mebazaa A, Landoni G, Grossini E, Caimmi P, Morelli A, Guarracino F, Schwinger RH, Meyer S, Algotsson L, Wikstrom BG, Jorgensen K, Filippatos G, Parissis JT, Gonzalez MJ, Parkhomenko A, Yilmaz MB, Kivikko M, Pollesello P, Follath F (2012) Levosimendan: molecular mechanisms and clinical implications: consensus of experts on the mechanisms of action of levosimendan. Int J Cardiol 159(2):82-87. https://doi.org/10.1016/j.jicar d.2011.07.022

16. Follath F, Cleland JG, Just H, Papp JG, Scholz H, Peuhkurinen K, Harjola VP, Mitrovic V, Abdalla M, Sandell EP, Lehtonen L, Steering C, Investigators of the Levosimendan Infusion versus Dobutamine S (2002) Efficacy and safety of intravenous levosimendan compared with dobutamine in severe low-output heart failure (the LIDO study): a randomised doubleblind trial. Lancet 360(9328):196-202

17. van Hees HW, Dekhuijzen PN, Heunks LM (2009) Levosimendan enhances force generation of diaphragm muscle from patients with chronic obstructive pulmonary disease. Am J Respir Crit Care Med 179(1):41-47. https://doi.org/10.1164/rccm.200805-7320C

18. Doorduin J, Sinderby CA, Beck J, Stegeman DF, van Hees HW, van der Hoeven JG, Heunks LM (2012) The calcium sensitizer levosimendan improves human diaphragm function. Am J Respir Crit Care Med 185(1):90-95. https://doi.org/10.1164/rccm.201107-12680C

19. Doorduin J, Sinderby CA, Beck J, van der Hoeven JG, Heunks LM (2015) Assisted ventilation in patients with acute respiratory distress syndrome: lung-distending pressure and patient-ventilator interaction. Anesthesio-ogy 123(1):181-190. https://doi.org/10.1097/ALN.0000000000000694

20. Sinderby C, Lindstrom L, Grassino AE (1995) Automatic assessment of electromyogram quality. J Appl Physiol (1985) 79(5):1803-1815. https:// doi.org/10.1152/jappl.1995.79.5.1803

21. Sinderby CA, Beck JC, Lindstrom LH, Grassino AE (1997) Enhancement of signal quality in esophageal recordings of diaphragm EMG. J Appl Physiol (1985) 82(4):1370-1377. https://doi.org/10.1152/jappl.1997.82.4.1370
22. Sinderby C, Beck J, Spahija J, Weinberg J, Grassino A (1998) Voluntary activation of the human diaphragm in health and disease. J Appl Physiol (1985) 85(6):2146-2158. https://doi.org/10.1152/jappl.1998.85.6.2146

23. Doorduin J, Roesthuis $L H$, Jansen D, van der Hoeven JG, van Hees HWH, Heunks LMA (2018) Respiratory muscle effort during expiration in successful and failed weaning from mechanical ventilation. Anesthesiology 129(3):490-501. https://doi.org/10.1097/ALN.00000000000002256

24. Alberti A, Gallo F, Fongaro A, Valenti S, Rossi A (1995) P0.1 is a useful parameter in setting the level of pressure support ventilation. Intensive Care Med 21(7):547-553

25. Farmakis D, Alvarez J, Gal TB, Brito D, Fedele F, Fonseca C, Gordon AC, Gotsman I, Grossini E, Guarracino F, Harjola VP, Hellman Y, Heunks L, Ivancan V, Karavidas A, Kivikko M, Lomivorotov V, Longrois D, Masip J, Metra M, Morelli A, Nikolaou M, Papp Z, Parkhomenko A, Poelzl G, Pollesello P, Ravn HB, Rex S, Riha H, Ricksten SE, Schwinger RHG, Vrtovec B, Yilmaz MB, Zielinska M, Parissis J (2016) Levosimendan beyond inotropy and acute heart failure: evidence of pleiotropic effects on the heart and other organs: an expert panel position paper. Int J Cardiol 222:303-312. https:// doi.org/10.1016/j.ijcard.2016.07.202

26. van Hees HW, Andrade Acuna G, Linkels M, Dekhuijzen PN, Heunks LM (2011) Levosimendan improves calcium sensitivity of diaphragm muscle fibres from a rat model of heart failure. Br J Pharmacol 162(3):566-573. https://doi.org/10.1111/j.1476-5381.2010.01048.x

27. Shi ZH, Jonkman A, de Vries H, Jansen D, Ottenheijm C, Girbes $A$, Spoelstra-de Man A, Zhou JX, Brochard L, Heunks L (2019) Expiratory muscle dysfunction in critically ill patients: towards improved understanding. Intensive Care Med 45(8):1061-1071. https://doi.org/10.1007/ s00134-019-05664-4

28. Chang W, Xie JF, Xu JY, Yang Y (2018) Effect of levosimendan on mortality in severe sepsis and septic shock: a meta-analysis of randomised trials. BMJ Open 8(3):e019338. https://doi.org/10.1136/bmjopen-2017-019338

29. Jansen D, Jonkman AH, Roesthuis L, Gadgil S, van der Hoeven JG, Scheffer GJ, Girbes A, Doorduin J, Sinderby CS, Heunks LMA (2018) Estimation of the diaphragm neuromuscular efficiency index in mechanically ventilated critically ill patients. Crit Care 22(1):238. https://doi.org/10.1186/ s13054-018-2172-0

30. Jonkman AH, Jansen D, Gadgil S, Keijzer C, Girbes ARJ, Scheffer GJ, van der Hoeven JG, Tuinman PR, Spoelstra-de Man AME, Sinderby CS, Heunks LMA (2019) Monitoring patient-ventilator breath contribution in critically ill patients during neurally-adjusted ventilatory assist: reliability and improved algorithms. J Appl Physiol (1985). https://doi.org/10.1152/jappl physiol.00071.2019

31. Gordon AC, Perkins GD, Singer M, MCAuley DF, Orme RM, Santhakumaran S, Mason AJ, Cross M, Al-Beidh F, Best-Lane J, Brealey D, Nutt CL, McNamee JJ, Reschreiter H, Breen A, Liu KD, Ashby D (2016) Levosimendan for the prevention of acute organ dysfunction in sepsis. N Engl J Med 375(17):1638-1648. https://doi.org/10.1056/NEJMoa1609409

32. Russell AJ, Hartman JJ, Hinken AC, Muci AR, Kawas R, Driscoll L, Godinez G, Lee KH, Marquez D, Browne WFT, Chen MM, Clarke D, Collibee SE, Garard M, Hansen R, Jia Z, Lu PP, Rodriguez H, Saikali KG, Schaletzky J, Vijayakumar V, Albertus DL, Claflin DR, Morgans DJ, Morgan BP, Malik FI (2012) Activation of fast skeletal muscle troponin as a potential therapeutic approach for treating neuromuscular diseases. Nat Med 18(3):452-455. https://doi.org/10.1038/nm.2618

33. Shefner JM, Cudkowicz ME, Hardiman O, Cockroft BM, Lee JH, Malik FI, Meng L, Rudnicki SA, Wolff AA, Andrews JA, Vitality-Als Study G (2019) A phase III trial of tirasemtiv as a potential treatment for amyotrophic lateral sclerosis. Amyotroph Lateral Scler Frontotemporal Degener 13:1-11. https://doi.org/10.1080/21678421.2019.1612922

34. Doorduin J, van Hees HW, van der Hoeven JG, Heunks LM (2013) Monitoring of the respiratory muscles in the critically ill. Am J Respir Crit Care Med 187(1):20-27. https://doi.org/10.1164/rccm.201206-1117CP 